\title{
GTP avoidance in Tetrahymena thermophila requires tyrosine kinase activity, intracellular calcium, NOS, and guanylyl cyclase
}

\author{
Janine Bartholomew • Johnathan Reichart • \\ Romie Mundy • Jacquelyn Recktenwald • \\ Shannon Keyser $\cdot$ Mark Riddle $\cdot$ Heather Kuruvilla
}

Received: 25 September 2006 / Accepted: 2 February 2007 / Published online: 24 February 2007

(C) Springer Science + Business Media B.V. 2007

\begin{abstract}
Guanosine 5'-triphosphate (GTP) is a chemorepellent in Tetrahymena thermophila that has been shown to stimulate cell division as well as ciliary reversal. Previous studies have proposed that GTP avoidance is linked to a receptor-mediated, calcium-based depolarization. However, the intracellular mechanisms involved in GTP avoidance have not been previously documented. In this study, we examine the hypothesis that GTP signals through a tyrosine kinase pathway in T. thermophila. Using behavioral assays, enzyme immunosorbent assays, Western blotting, and immunofluorescence, we present data that implicate a tyrosine kinase, phospholipase $\mathrm{C}$, intracellular calcium, nitric oxide synthase (NOS) and guanylyl cyclase in GTP signaling. The tyrosine kinase inhibitor genistein eliminates GTP avoidance in Tetrahymena in behavioral assays. Similarly, pharmacological inhibitors of phospholipase C, NOS, and guanylyl cyclase all eliminated Tetrahymena avoidance to GTP. Immunofluorescence data shows evidence of tyrosine kinase activity in the cilia, suggesting that this enzyme activity could be directly involved in ciliary reversal.
\end{abstract}

Keywords Chemorepellent · Extracellular nucleotide ·

Purine metabolism

\begin{tabular}{|c|c|}
\hline \multicolumn{2}{|c|}{ Abbreviations } \\
\hline EIA & Enzyme immunosorbent assay \\
\hline cGMP & Guanosine 3'3;5'monophosphate \\
\hline GDP- $\beta-S$ & Guanosine-5'-O- (2-thio)diphosphate \\
\hline
\end{tabular}

J. Bartholomew $\cdot$ J. Reichart $\cdot$ R. Mundy $\cdot$ J. Recktenwald ·

S. Keyser $\cdot$ M. Riddle $\cdot$ H. Kuruvilla $(\bowtie)$

Department of Science and Mathematics, Cedarville University,

Cedarville, OH 45314, USA

e-mail: heatherkuruvilla@cedarville.edu

$\begin{array}{ll}\text { GTP- } \gamma \text {-S } & \text { Guanosine-5'-O-(3-thio)triphosphate } \\ \text { PKC } & \text { Protein kinase C } \\ \text { NO } & \text { Nitric oxide } \\ \text { NOS } & \text { Nitric oxide synthase } \\ \text { Rp-8-Br- } & \text { Rp-8-Bromoguanosine-3',5'-cyclic } \\ \text { cGMPs } & \text { monophosphorothioate } \\ \text { TNP-GTP } & \text { 2'-(or } 3 \text { ')- } O \text {-(2,4,6-trinitrophenyl)guanosine } \\ & \text { 5'-triphosphate }\end{array}$

\section{Introduction}

Chemorepellents are molecules that inhibit or repel the migration of individual cells. In protozoans, chemorepellents are hypothesized to serve a defense mechanism, helping the organism to avoid predation and environmental hazards. For example, a damaged Tetrahymena thermophila cell may leak cytosolic purines such as adenosine triphosphate (ATP) or guanosine 5'-triphosphate (GTP) into the surrounding environment, causing other cells to avoid the area, thereby avoiding the source of damage to the original cell and increasing the survival rate of the species $[1,2]$. It is possible that cytosolic purines may be secreted by these organisms as a means of communication between cells (analogous to paracrine secretion) or in order to trigger second-messenger pathways within the cell doing the secretion (analogous to autocrine secretion). At this time, secretion of purine nucleotide by Tetrahymena has not been documented, although Tetrahymena have been shown to secrete a number of enzymes and peptides.

In T. thermophila, extracellular GTP is a known chemorepellent $[1,3,4]$. GTP causes depolarization in the somatic membrane [2], which has been proposed to trigger opening of the voltage-dependent calcium channels in the ciliary 
membrane [2]. The increase in $\mathrm{Ca}^{2+}$ concentration causes the cilia to reverse their direction [1], resulting in a disruption of normal swimming. This "avoidance reaction" [1] is marked by jerky movements, backward swimming, or spinning. This chemokinetic response involves a series of avoidance reactions, resulting in a "biased random walk," which orients the organism away from the source of the repellent [3]. Avoidance to chemorepellents may be quantified by observing the response of single cells exposed to repellent using a dissection microscope.

T. thermophila avoid micromolar concentrations of GTP [1]. An in vivo binding assay using [32P] GTP showed the $\mathrm{K}_{\mathrm{D}}$ for GTP binding to intact $T$. thermophila is $21 \pm 2.5 \mathrm{nM}$. GTP binds to its receptor with high affinity, and binding is saturable as well as reversible [1], all of which are characteristic of membrane receptors. Fluorescent staining with 2'-(or 3')-O-(2,4,6-trinitrophenyl) (TNP)-GTP has shown GTP binding on the cilia and cell surface of $T$. thermophila [4]. However, the second messenger pathways involved in GTP signaling have not been previously described.

Recently, Iwamoto and Nakaoka [4] found that addition of extracellular GTP to the medium induces cell division in T. thermophila, a result consistent with a tyrosine kinase signaling mechanism, as tyrosine kinases are involved in many major mitotic pathways. Tyrosine phosphorylation has previously been shown to modulate the interaction of calmodulin with target proteins, including protein phosphatase 2B (calcineurin) and neuronal nitric oxide synthase (nNOS) in an in vitro assay [5]. Tyrosine kinase activity has also been shown to activate phospholipase C, NOS (via protein kinase C), and guanylyl cyclase in the rat ileum [6]. Tyrosine kinases are frequently associated with activation of phospholipase $\mathrm{C}-\gamma$, and with release of calcium from internal stores via the $\mathrm{IP}_{3}$ pathway [7].

In our current study, we examined the hypothesis that GTP signals through a tyrosine kinase pathway in $T$. thermophila. Our data confirm this hypothesis. In addition to tyrosine kinase signaling, we found that phospholipase $\mathrm{C}$, intracellular calcium stores, NOS, and guanylyl cyclase are necessary for behavioral avoidance to occur. All of these second messengers are consistent with the existence of a tyrosine kinase signaling pathway in $T$. thermophila.

\section{Materials and methods}

Cell cultures

T. thermophila, strain B2086, a generous gift from T.M. Hennessey (SUNY-Buffalo) were used for all of the experiments. Cells were grown at $25^{\circ} \mathrm{C}$ in the axenic medium of Dentler [8] without shaking. Two-day-old cell cultures were used for all assays described below.
Chemicals and solutions

Behavioral assays were carried out in a buffer of $\mathrm{pH} 7.0$ containing $10 \mathrm{mM}$ Trizma base, $0.5 \mathrm{mM}$ MOPS, and $50 \mu \mathrm{M} \mathrm{CaCl}{ }_{2}$. All repellents and inhibitors used were dissolved in this buffer. Compounds that were insoluble in aqueous solutions were first dissolved in a small quantity of dimethylsulfoxide (DMSO) and then diluted 1:1,000 or more into the buffer and vortexed vigorously. The chemorepellent guanosine-5'-O-(3-thio)triphosphate (GTP- $\gamma-\mathrm{S})$ was obtained from Alexis Biochemicals (San Diego, CA, USA), along with the G-protein inhibitor pertussis toxin. The tyrosine kinase inhibitor genistein was obtained from Acros Organics (New Jersey, USA). Calphostin C [a protein kinase $\mathrm{C}(\mathrm{PKC})$ inhibitor], diadzein a control for genistein inhibition), guanosine-5'-O- (2-thiodiphosphate) (GDP- $\beta$-S) (a G-protein inhibitor), Rp-8-Bromoguanosine3',5'-cyclic monophosphorothioate (Rp-8-Br-cGMPs) (a competitive inhibitor of $\mathrm{PKG}), 1-(6-(17 \beta-3-$ methoxyestra1,3,5(10)-trien-17-yl) amino)hexyl)-1H-pyrrole-2,5-dione (U73122) (a phospholipase C inhibitor), NG-monomethylL-arginine (L-NMMA), and N-(3-(Aminomethyl)benzyl) acetamidine (1400W) (NOS inhibitors), 4H-8-bromo-1,2,4oxadiazolo(3,4-d) benz(b)(1,4)oxazin-1-one (NS2028) (a PKG inhibitor), and the Quantizyme nitric oxide (NO) assay kit were purchased from BIOMOL Research Laboratories (Plymouth Meeting, PA, USA). The polyclonal antiphosphotyrosine antibody was purchased from Upstate (Lake Placid, NY, USA); 30X Tris-buffered saline (TBS) and 30X TBS/nonidet P40 (NP40) were obtained from Modern Biology (West Lafayette, IN, USA). The guanosine 3'3;5'monophosphate (cGMP) emzyme immunosorbent assay (EIA) kit was purchased from Cayman Chemical (Ann Arbor, MI, USA). Sodium metavanadate (a phosphatase inhibitor) and theophylline (a phosphodiesterase inhibitor) were obtained from Sigma Chemical (St. Louis, MO, USA). All other chemicals were purchased from Sigma as well.

\section{Behavioral assays}

In vivo behavioral assays were carried out as previously described $[1,9,10]$. Briefly, cells were washed in buffer, and $300 \mu \mathrm{l}$ of cell suspension was transferred to the first well of a three-well spot microtiter plate. Cells were then individually transferred by micropipette to the second well, which contained $300 \mu$ l of the test concentration of inhibitor dissolved in buffer. After at least 10-15 min of incubation time, individual cells were transferred to the third well, which contained $300 \mu \mathrm{l} \mathrm{GTP- \gamma -S}$ and the test concentration of inhibitor. Each cell was briefly observed (1-5 s) for signs of avoidance. Avoidance behavior was characterized by jerky, backward movements; swimming in 
small, tight circles; sudden reversal of swimming direction; or any deviation from the normal helical swimming pattern of $T$. thermophila.

\section{Western blots}

Western blots were performed as follows: For each sample, $10 \mathrm{ml}$ of the same 2-day-old culture was washed $3 \times$ in behavioral buffer; $100 \mu \mathrm{M}$ GTP- $\gamma-\mathrm{S}$ (the concentration required to elicit $100 \%$ avoidance) was added to the tube of cells marked GTP. The control tube received only buffer; no GTP was added. Both tubes were immediately extracted with $0.1 \%$ sodium dodecyl sulphate (SDS) in the presence of $1 \mathrm{mM}$ sodium orthovanadate for $30 \mathrm{~min}$ at $4{ }^{\circ} \mathrm{C}$. Extracts were spun at $16,000 \mathrm{~g}$ at $4^{\circ} \mathrm{C}$ for $30 \mathrm{~min}$ to precipitate insoluble components. Supernatant was collected, and $5 \times$ loading buffer was applied in preparation for SDS polyacrylamide gel electrophoresis (PAGE); $100 \mu \mathrm{l}$ of each sample was applied to a $10 \%$ SDS-PAGE. Amount of protein loaded onto the gel was standardized using the BIORAD protein assay; in addition, a control, Coomassiestained gel, was run to show that equal amounts of protein were loaded into each well. Proteins were transferred from the SDS-PAGE to nitrocellulose for $30 \mathrm{~min}$ at $150 \mathrm{~mA}$. Blots were then blocked overnight in a $3 \%$ solution of powdered milk. Blots were incubated with a 1:1,000 dilution of polyclonal phosphotyrosine antibody in the presence of $3 \%$ powdered milk for $1.5 \mathrm{~h}$, washed $3 \times$ in TBS, then incubated with a 1:100 dilution of alkaline phosphate conjugated anti-rabbit antibody for $1.5 \mathrm{~h}$ in the presence of $3 \%$ powdered milk. Blots were then washed $3 \times$ with TBS and incubated for $5 \mathrm{~min}$ in an alkaline phosphatase buffer containing $100 \mathrm{mM} \mathrm{NaCl}, 5 \mathrm{mM}$ $\mathrm{MgCl}_{2}, 100 \mathrm{mM}$ Trizma base, $\mathrm{pH} 9.5$ with hydrogen chloride $(\mathrm{HCl})$. Alkaline phosphatase buffer was then removed, and blots were developed using the Sigma-Fast system until bands were visible.

\section{EIA assays}

NO assays were carried out using 2-day-old cell cultures. Cells were washed twice in buffer and diluted to a final concentration of approximately 720 cells $/ \mathrm{ml}$. Cells were exposed to $100 \mu \mathrm{M}$ GTP- $\gamma-\mathrm{S}$ for approximately $30 \mathrm{~s}$, then spun down in a bench-top microcentrifuge for $30 \mathrm{~s}$. Control cells were spun under identical conditions except that no GTP was added to the solution. Supernatant from both sets of cells was analyzed for NO using a kit from BIOMOL according to the manufacturer's instructions.

cGMP assays were carried out using 2-day-old cell cultures. Cells were concentrated to approximately $7.66 \times$ $10^{6}$ cells $/ \mathrm{ml}$ in order to maximize cGMP production. Cells were exposed to $100 \mu \mathrm{M}$ GTP for approximately $30 \mathrm{~s}$, then immediately lysed by freezing in liquid nitrogen and thawing. Theophylline $(1 \mathrm{mM})$ was added to the lysate to inhibit phosphodiesterases. Lysate was spun at $16,000 \mathrm{~g}$ for $30 \mathrm{~min}$. Control cells were treated in identical fashion except for the addition of GTP. Supernatant from both sets of cells was assayed for cGMP using a kit from Cayman Chemicals according to the manufacturer's instructions.

Immunofluorescence

Ten milliliters of 2-day-old cells were starved overnight in behavioral buffer then washed $3 \times$ in behavioral buffer and concentrated down into $2 \mathrm{ml}$. Mucocysts were removed by adding Alcian Blue GX to a final concentration of $0.05 \%$, then adding nine volumes of $0.25 \%$ proteose peptone [11]. Mucocysts were allowed to precipitate by standing the tube in a rack for $10 \mathrm{~min}$. Supernatant (including cells) was removed from the top of the tube. The cells were then washed $3 \times$ in behavioral buffer to remove any remaining mucocysts or Alcian Blue and concentrated down into $3 \mathrm{ml}$ total; $1 \mathrm{ml}$ of cells was set aside as the control cells. Another milliliter of cells was incubated with $100 \mu \mathrm{M}$ GTP- $\gamma$-S. A third aliquot was incubated with $100 \mu \mathrm{g} / \mathrm{ml}$ genistein prior to GTP treatment. Immediately, all three aliquots of cells were fixed in $3.7 \%$ formaldehyde (from $37 \%$ stock diluted into behavioral buffer) with gentle shaking for $20 \mathrm{~min}$. Cells were washed $3 \times$ in $1 \times \mathrm{TBS} /$ NP40 (Modern Biology) then incubated with a 1:100 dilution of polyclonal antibody in $1 \times$ TBS/NP40 for $1.5 \mathrm{~h}$. Cells were again washed $3 \times$ in $1 \times$ TBS/NP40 then incubated in a 1:100 dilution of fluorescein isothiocyanate (FITC)-conjugated goat anti-rabbit IgG (ICN Biomedicals) for $1.5 \mathrm{~h}$. Cells were washed $3 \times$ in $1 \times$ TBS before being viewed under a Nikon microscope at $400 \times$. Cells were photographed using a SPOT digital camera using a 10-s exposure for each photograph.

\section{Results}

GTP- $\gamma-\mathrm{S}$ is a chemorepellent in Tetrahymena, with a minimum concentration of $100 \mu \mathrm{M}$ required for $100 \%$ avoidance (Fig. 1). This concentration was used in the inhibition studies that follow as well as in our biochemical studies. We used GTP- $\gamma$-S in our experiments rather than GTP to minimize the effects of the ecto-ATPase upon the assays [3]. However, the activity of apyrases and other ectoenzymes may still have degraded some of the GTP- $\gamma$-S before it could reach its intended receptor. The concentration of GTP- $\gamma-\mathrm{S}$ required in order to achieve $100 \%$ avoidance in this study was $5 \times$ higher than that previously published [1]; however, considering that the cell line and growth conditions were different than those published 


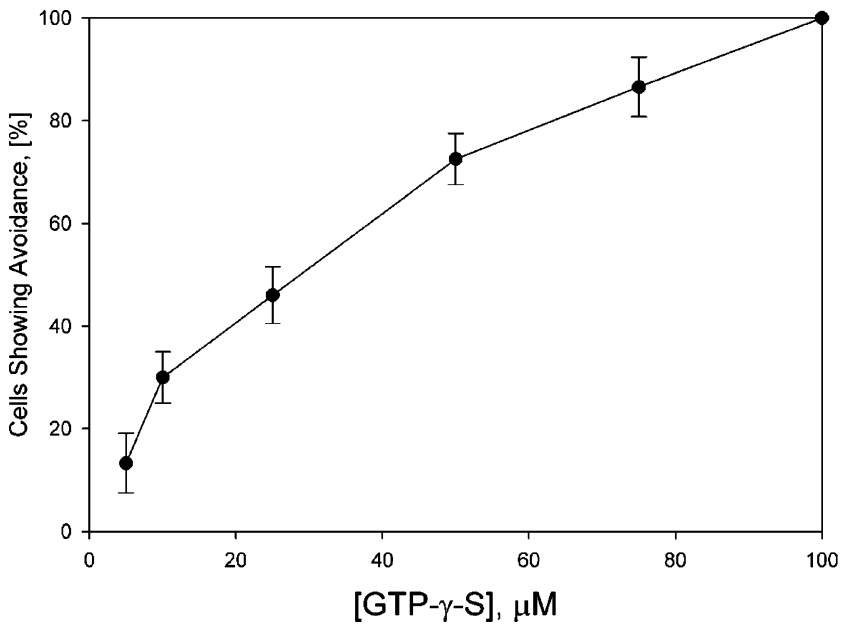

Fig. 1 Guanosine-5'-O-(3-thio)triphosphate (GTP- $\gamma-\mathrm{S})$ is an effective chemorepellent in Tetrahymena. In vivo behavioral bioassays (see "Materials and methods") were used to show the concentration dependencies for avoidance reactions to GTP- $\gamma-\mathrm{S}$. The percentage of cells showing avoidance was determined by observation of a single cell after transfer to the test solution. Each trial consisted of ten cells, which were individually scored as to whether or not avoidance occurred. Each point represents the mean \pm standard deviation (SD) of at least three trials. Error bars, representing the standard deviation, are shown for each point. Minimum concentration required to give $100 \%$ avoidance was $100 \mu \mathrm{M}$ for GTP- $\gamma-\mathrm{S}$. This concentration was used in the inhibition studies that follow. The $\mathrm{EC}_{50}$ of this compound was approximately $30 \mu \mathrm{M}$

earlier, this finding is not unexpected. The $\mathrm{EC}_{50}$ of GTP- $\gamma-\mathrm{S}$ in this study was approximately $30 \mu \mathrm{M}$.

To determine whether a tyrosine kinase activity was involved in GTP avoidance, we used the tyrosine kinase inhibitor, genistein (Fig. 2). Genistein itself did not cause avoidance reactions, nor was it toxic to the cells. Baseline avoidance of $\sim 20 \%$ [9] to $100 \mu \mathrm{M} \mathrm{GTP}-\gamma$-S was seen at a genistein concentration of $100 \mu \mathrm{g} / \mathrm{ml}$. The inhibition constant (IC) $)_{50}$ of genistein was approximately $40 \mu \mathrm{g} / \mathrm{ml}$. Another phytoestrogen, daidzein, served as a control for nonspecific side effects of genistein. As seen in Fig. 2, this compound had no measurable effect on avoidance at the tested concentrations, suggesting that the inhibitory effect of genistein was indeed due to its tyrosine kinase inhibition and not attributable to some side effect of the drug.

As an additional control for specificity, we tested whether genistein had any effect on the transduction of another chemorepellent, adenosine 5'-O-(3-thio)triphosphate (ATP- $\gamma-\mathrm{S}$ ). We used $150 \mu \mathrm{M}$ ATP- $\gamma-\mathrm{S}$, a concentration that normally causes $100 \%$ avoidance in $T$. thermophila [12]. When cells exposed to ATP- $\gamma$-S were first incubated for $10-15 \mathrm{~min}$ in $100 \mu \mathrm{g} / \mathrm{ml}$ genistein, no measurable effect on avoidance was seen. Cells continued to avoid $150 \mu \mathrm{M}$ ATP- $\gamma-\mathrm{S}$ at a rate of $96.6+5.8 \%(n \geq 3)$. Genistein also failed to affect avoidance to the chemorepellent pituitary adenylate cyclase-activating polypeptide (PACAP). When testing $0.1 \mu \mathrm{M}$ PACAP, which normally causes $100 \%$ avoidance in T. thermophila [9], we found that prior incubation with $100 \mu \mathrm{g} / \mathrm{ml}$ genistein did not markedly affect avoidance. Cells continued to avoid $0.1 \mu \mathrm{M}$ PACAP at a rate of $96.6+5.8 \%(n \geq 3)$. These data suggest that tyrosine kinase activation is specifically related to GTP exposure rather than being a general response to chemorepellent exposure.

In an attempt to localize the phosphotyrosines within the cell, immunofluorescence experiments were performed using a polyclonal antiphosphotyrosine antibody. Three separate trials were done with this antibody, and representative photographs are compiled in Fig. 3a-c. GTP-exposed cells (Fig. 3b) showed higher overall fluorescence intensity than did the controls and genistein-treated GTP-exposed cells (Fig. 3a,c). Ciliary staining was seen in the GTPexposed cells, along with punctuate staining of the cytosol. The control and genistein-treated GTP-exposed cells showed the same cytosolic staining pattern, but ciliary staining was not detected in these control groups, perhaps because the overall fluorescence level of these cells was so low.

To determine which proteins were being phosphorylated by the tyrosine kinase in response to GTP- $\gamma$-S, we also performed several Western blots of whole-cell extract obtained from control and GTP- $\gamma$-S -treated cells using the polyclonal antiphosphotyrosine antibody as a probe. Protein extracts were standardized so that lanes were loaded equally, and a control, Coomassie-stained gel, was also run to control for lane-loading artifacts (data not shown). A representative Western blot is pictured in Fig. 3d. Both GTP-treated and control cells showed similar staining at

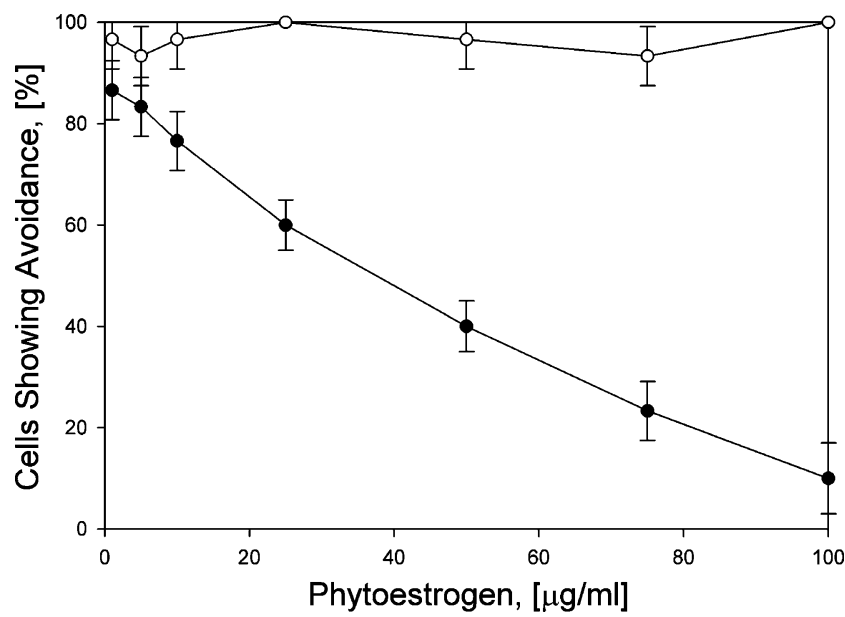

Fig. 2 The tyrosine kinase inhibitor, genistein, blocks avoidance to $100 \mu \mathrm{M}$ guanosine-5'-O-(3-thio)triphosphate (GTP- $\gamma-\mathrm{S})$ in Tetrahymena. The phytoestrogens genistein (closed circles) and daidzein (open circles) were used as inhibitors of avoidance. Baseline avoidance was seen at a genistein concentration of $100 \mu \mathrm{g} / \mathrm{ml}$. The $\mathrm{IC}_{50}$ of genistein was approximately $40 \mu \mathrm{g} / \mathrm{ml}$. Daidzein served as a control for nonspecific effects of genistein and had no measurable effect on avoidance at the concentrations tested. Data shown represent the mean $+/-$ standard deviation (SD) for three or more trials 

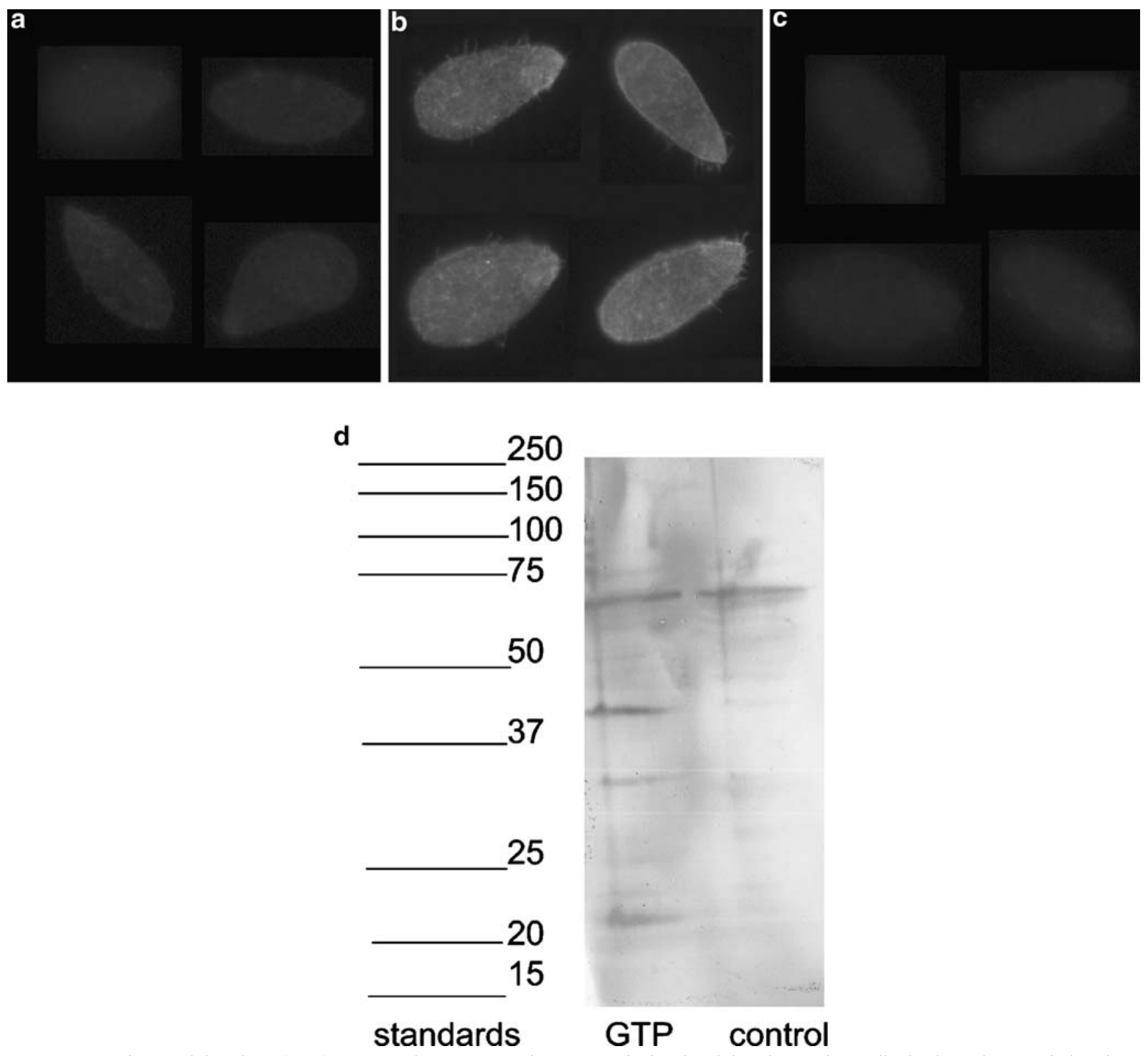

Fig. 3 Guanosine 5'-triphosphate (GTP) exposure increases tyrosine kinase activity in Tetrahymena. a-c Immunofluorescence labeling of phosphotyrosines in Tetrahymena is evidence of tyrosine kinase activity. Control (a), GTP-exposed (b), and genistein-treated GTPexposed cells (c) were fixed and labeled with a polyclonal antiphosphotyrosine antibody. GTP-exposed cells showed higher fluorescence intensity than did control cells and cells treated with the tyrosine kinase inhibitor genistein. In addition, GTP-exposed cells showed ciliary staining in addition to punctuate staining of the cytosol. Total magnification $400 \times$. Cell length $\sim 50 \mu \mathrm{m}$. d Western blot of whole-cell extract obtained from control and GTP-exposed cells using

$66 \mathrm{kDa}$. However, increased phosphotyrosine levels were seen in the GTP- $\gamma$-S-treated cells at 42,35 , and $21 \mathrm{kDa}$, consistent with tyrosine kinase activity. These bands were also present in the control cell extract; however, the phosphorylation level in these lanes was so low that they were barely detectable with our staining procedure. Addi-

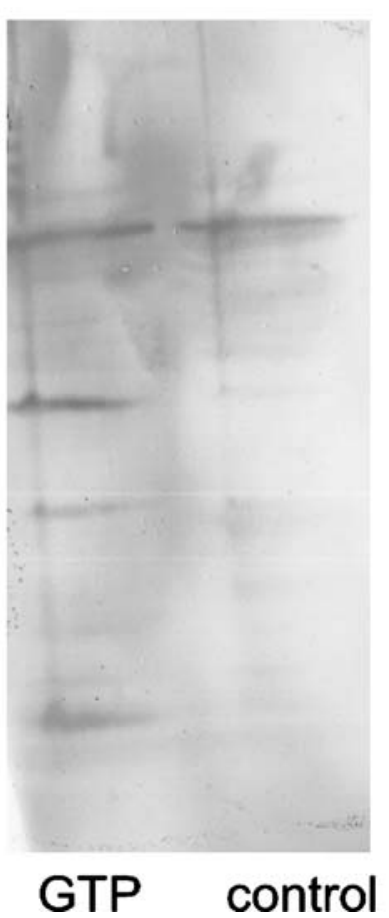

a polyclonal antiphosphotyrosine antibody shows increased phosphorylation levels in extract taken from GTP-exposed cells (lane 2) relative to extract from control cells (lane 3). A 66-kDa phosphoprotein stained similarly in both the GTP and control lanes, whereas bands of 42,35 , and $21 \mathrm{kDa}$ were more heavily stained in the GTP lane relative to the control lane. Molecular weight markers are shown in the first lane (molecular weights in $\mathrm{kDa}$ ). A Coomassie-stained sodium dodecyl sulphate polyacrylamide gel electrophoresis (SDSPAGE) run as a loading control showed equivalent staining of proteins in all lanes (not shown)

tional bands were also seen in both the GTP-exposed and the control lanes; however, they were also too light to be measurable. A more sensitive assay, such as chemiluminescence based Western blot detection, might help to give a more complete profile of the phosphotyrosine-containing proteins shown in this procedure. 
In many cells, activation of a tyrosine kinase activates phospholipase $\mathrm{C}-\gamma$. We used the phospholipase $\mathrm{C}$ inhibitor, U73122, to determine whether phospholipase $\mathrm{C}$ might be involved in GTP avoidance. GTP avoidance was effectively eliminated at a U73122 concentration of $1 \mu \mathrm{M}$. This concentration was ten times lower than that used to inhibit phospholipase $\mathrm{C}$ in molluscan ciliary cells [12]. The $\mathrm{IC}_{50}$ of this compound was approximately $0.001 \mu \mathrm{M}$. Phospholipase $\mathrm{C}$ activates the PKC pathway through the generation of diacylglycerol (DAG) and inositol 1,4,5 trisphosphate $\left(\mathrm{IP}_{3}\right)$. PKC is then activated by DAG binding in the presence of calcium. To determine whether PKC was involved in GTP avoidance, we used the PKC inhibitor calphostin $\mathrm{C}$, which competes for DAG binding to PKC. In the presence of $10 \mu \mathrm{M}$ calphostin $\mathrm{C}$, avoidance to $100 \mu \mathrm{M}$ GTP- $\gamma-\mathrm{S}$ was reduced only to $96.6+/-5.8 \%$, compared with $100 \%$ avoidance in control cells. This concentration of calphostin C eliminated avoidance to $150 \mu \mathrm{M}$ ATP- $\gamma$-S [13]. Because calphostin $\mathrm{C}$ had no measurable effect on GTP avoidance, we concluded that PKC activy is not required for GTP signaling. It is very likely that the two second messengers, $\mathrm{IP}_{3}$ and $\mathrm{DAG}$, are generated by phospholipase $\mathrm{C}$ and that PKC is activated, but that PKC targets cellular substrates that are not directly involved in ciliary reversal.

Because calcium signaling is often associated with tyrosine kinase pathways and because calcium influx is associated with GTP exposure [2], we decided to eliminate calcium rom cells using the membrane-permeable calcium chelator 1,2-bis-(o-Aminophenoxy)-ethane-N,N,N',N'tetraacetic acid, tetra (acetoxymethyl) ester (BAPTA-AM). As seen in Fig. 5a, exposure to this calcium chelator eliminated avoidance in a concentration-dependent manner, with baseline avoidance seen at a BAPTA-AM concentration of $5 \mu \mathrm{g} / \mathrm{ml}$. This result was certainly not surprising, as all known chemorepellents that have been studied electrophysiologically in Tetrahymena have elicited depolarizations $[2,14,15]$ that have been proposed to be linked to calcium. Because our data indicated that phospholipase $\mathrm{C}$ was involved in GTP avoidance, we decided to test the hypothesis that internal calcium stores may also contribute to avoidance, consistent with the liberation of $\mathrm{IP}_{3}$ from the plasma membrane. We used an inhibitor of the endoplasmic reticulum (ER) calcium ATPase, thapsigargin, to deplete ER calcium stores to determine whether these stores were necessary for avoidance. Baseline avoidance to GTP was seen at a thapsigargin concentration of 1,000 nM (Fig. 5b). The $\mathrm{IC}_{50}$ of thapsigargin was approximately $1 \mathrm{nM}$.

$\mathrm{NO}$ is another second messenger sometimes associated with tyrosine kinases $[5,17]$ and often associated with calcium signaling $[5,18]$. In addition, NO has been found to be a critical second messenger in the Tetrahymena response to both ATP [13] and PACAP-38 [18]. To determine whether NO was involved in GTP signaling, we used the NOS inhibitors 1400W (Fig. 6a) and LNMMA (Fig. 6b). Both inhibitors blocked avoidance to $100 \mu \mathrm{M}$ GTP- $\gamma-\mathrm{S}$ in Tetrahymena, with baseline avoidance being reached at $100 \mathrm{nM}$ for $1400 \mathrm{~W}$ (Fig. 6a) and $50 \mu \mathrm{M}$ for L-NMMA (Fig. 6b). The $\mathrm{IC}_{50}$ of $1400 \mathrm{~W}$ was near $0.1 \mathrm{nM}$, whereas L-NMMA was approximately $3 \mu \mathrm{M}$.

To confirm the activity of NOS in GTP avoidance, we used the Quantizyme NO assay to determine whether there was a difference in NO metabolism between control and GTP-stimulated cells. Cells stimulated with $8 \mathrm{mg} / \mathrm{ml}$ GTP had a $146+-4.7 \%$ increase in NO levels over control cells, consistent with the inhibitor studies $(n=3)$.

In many cells, NO activates guanylyl cyclase, which then produces cGMP. Previous studies by Christensen et al. [20] described an NO-linked, possibly soluble guanylyl cyclase activity in $T$. thermophila. More recent studies, reviewed by Linder and Schultz [20], described a membrane-associated and calcium-dependent guanylyl cyclase in these organisms. To determine whether any guanylyl cyclase isoform was involved in GTP avoidance, we used NS2028, an inhibitor of guanylyl cyclase (Fig. 7a), as well as Rp-8-bromo-cGMPs, a competitive inhibitor of cGMP (Fig. 7b), in behavioral assays. NS2028 and Rp-8-bromocGMPs both blocked avoidance to $100 \mu \mathrm{M}$ GTP- $\gamma-\mathrm{S}$ in Tetrahymena. Baseline avoidance was obtained at $10 \mathrm{nM}$ NS2028 (Fig. 7a) and at $50 \mu \mathrm{M}$ Rp-8-bromo-cGMPs (Fig. 7b). The $\mathrm{IC}_{50}$ of NS2028 was approximately $0.05 \mathrm{nM}$ and of Rp-8-bromo-cGMPs near $7 \mu \mathrm{M}$. To confirm these results biochemically, we performed an EIA assay to determine whether GTP exposure resulted in elevated cGMP levels within Tetrahymena. Exposure to $5 \mathrm{mg} / \mathrm{ml}$ GTP resulted in a $1,119+/-4.2 \%$ increase above control cGMP levels $(n \geq 3)$, consistent with the hypothesis that GTP avoidance is linked to a guanylyl cyclase.

Based on the data we collected, we put together a provisional model of GTP signaling (Fig. 8). In our model, GTP binds to a receptor, which activates tyrosine kinase while interacting with a membrane calcium channel, causing a depolarization. Phospholipase $\mathrm{C}$ is activated, generating $\mathrm{IP}_{3}$, which allows calcium efflux from ER stores. The high cytosolic calcium interacts with some (unknown) isoform of NOS, guanylyl cyclase, and other calcium-binding proteins, ultimately resulting in ciliary reversal. Whereas some of the relationships between second messengers are still unknown, the model has been put together to stimulate thought and discussion and to make some order out of a complex pathway.

\section{Discussion}

The data we have compiled here are consistent with the hypothesis that the previously described GTP receptor [1] 


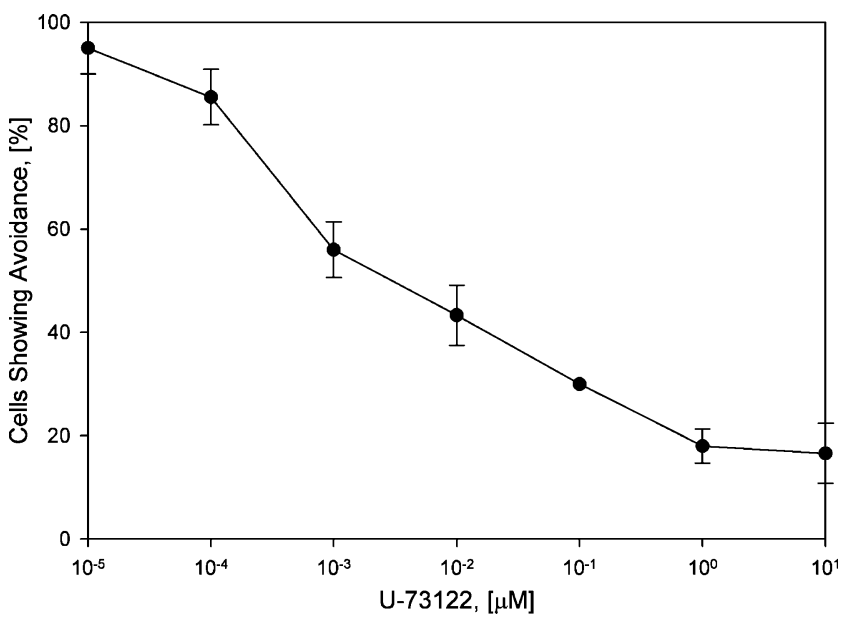

Fig. 4 The phospholipase $C$ inhibitor 1-(6-(17 $\beta-3$-methoxyestra-1,3,5 (10)-trien-17-yl) amino)hexyl)-1H-pyrrole-2,5-dione (U73122) blocks avoidance to $100 \mu \mathrm{M}$ guanosine-5'-O-(3-thio)triphosphate (GTP- $\gamma$-S) in Tetrahymena. Baseline avoidance was reached at a U73122 concentration of $1 \mu \mathrm{M}$. The inhibition constant $\mathrm{IC}_{50}$ of this compound was near $0.001 \mu \mathrm{M}$. Data shown is mean $+/-$ standard deviation (SD) of three or more trials

signals through a tyrosine kinase (Fig. 2, 3). The GTP signaling pathway also involves phospholipase C (Fig. 4), intracellular calcium (Fig. 5), NOS (Fig. 6), and guanylyl cyclase (Fig. 7). The proposed GTP signaling pathway is outlined in Fig. 8.

GTP is the first chemorepellent we have studied that does not signal through a G-protein-linked receptor, unlike ATP [13] and PACAP [18, 21]. In contrast to other repellents, GTP signaling is unaffected by either GDP- $\beta-S$ or pertussis toxin (unpublished data). GTP is also the only one of these three repellents whose signaling is eliminated by genistein (Fig. 2; see "Results"). Previously published cross-adaptation data [2] indicated that GTP and ATP signal through different receptors. These data are consistent with the previously published literature and add the observation that both receptors and second-messenger pathways for these two repellents appear to be different.

Multiple target proteins are phosphorylated in response to GTP exposure (Fig. 3d), yet the proteins remain unidentified except for molecular weight. Phosphotyrosine immunolocalization does not help us identify these proteins; however, the ciliary staining (Fig. 3b) opens up the possibility of direct interaction between tyrosine kinase activity and ciliary reversal. This is worthy of note, as Christensen et al. [22] report a similar increase in ciliary phosphotyrosine labeling after exposure to the chemoattractant insulin. However, in their report, the main protein that was phosphorylated was a $66 \mathrm{kDa}$ protein, which they discovered was homologous to the insulin receptor. In the case of GTP exposure, we saw no increase in labeling of the $66 \mathrm{kDa}$ protein (Fig. 3d). Taken together, these data raise the possibility that there are multiple tyrosine kinase pathways that act on cilia to increase forward swim speed in the case of a chemoattractant, or to cause ciliary reversal in the case of a chemorepellent. Becausxe there were multiple phosphotyrosine bands in our Western blot (Fig. 3d) and ciliary as well as cytosolic staining in our immunofluorescence (Fig. 3b), we see that GTP exposure has both ciliary and cytosolic effects. Ciliary reversal is seen immediately upon GTP exposure; however, other effects of GTP exposure, such as mitosis, are seen hours after GTP exposure [4]. Perhaps the cytosolic target proteins are involved in other, longer-term effects of GTP, such as mitosis.
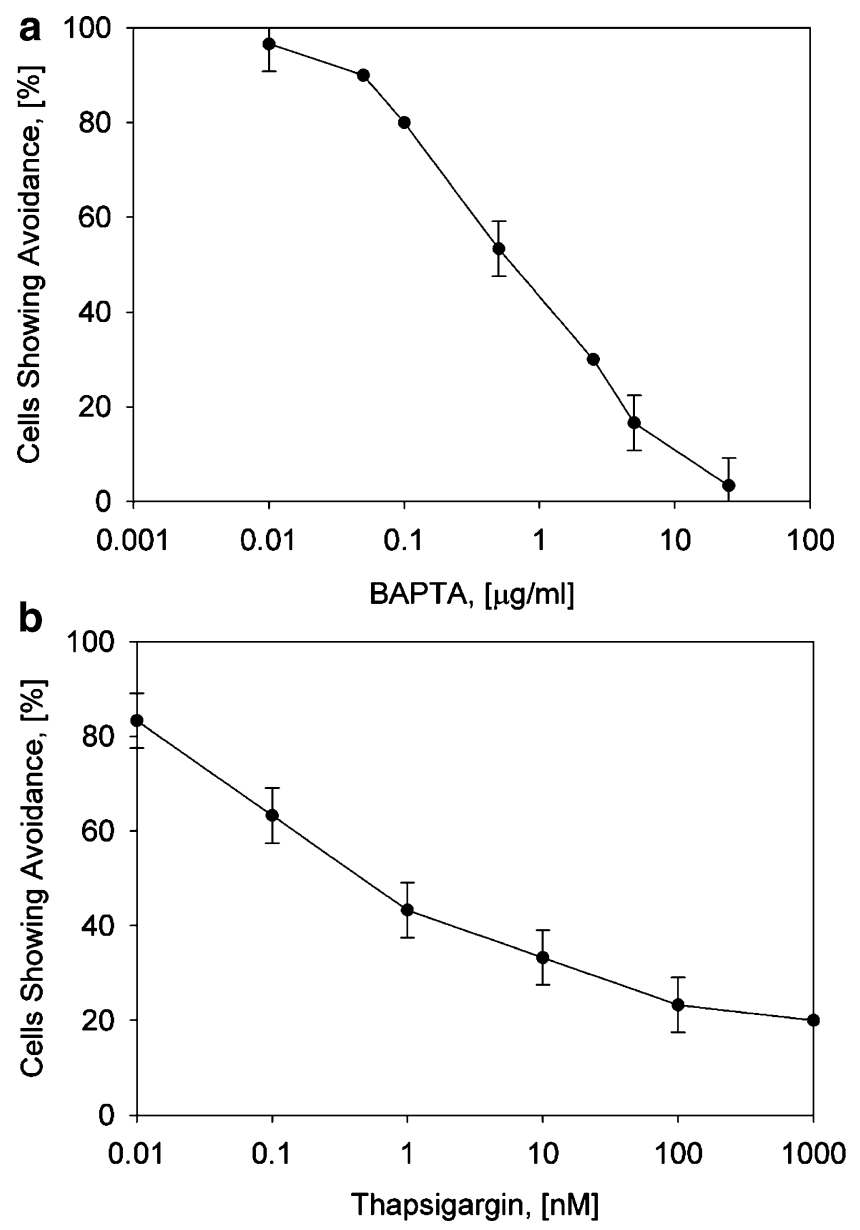

Fig. 5 Intracellular calcium is required for guanosine 5'-triphosphate (GTP) avoidance in Tetrahymena. a The membrane-permeable calcium chelator 1,2-bis-(o-Aminophenoxy)-ethane-N,N,N',N'-tetraacetic acid, tetra (acetoxymethyl) ester (BAPTA-AM) blocks avoidance to $100 \mu \mathrm{M}$ GTP- $\gamma$-S in Tetrahymena. Baseline avoidance was reached at a BAPTA-AM concentration of $5 \mu \mathrm{g} / \mu \mathrm{l}$. The inhibition constant $\mathrm{IC}_{50}$ of this compound was near $0.5 \mu \mathrm{g} / \mu \mathrm{l}$. Data shown is mean $+/-$ standard deviation (SD) of three trials. b The endothelial reticulum (ER) calcium adenosine triphosphatase (ATPase) inhibitor thapsigargin also blocks avoidance to $100 \mu \mathrm{M}$ guanosine-5'-O-(3-thio) triphosphate (GTP- $\gamma-\mathrm{S})$ in Tetrahymena.. Baseline avoidance was reached at a thapsigargin concentration of $1,000 \mathrm{nM}$. The $\mathrm{IC}_{50}$ of this compound was near $1 \mathrm{nM}$. Data shown is mean $+/-$ standard deviation (SD) of three or more trials 

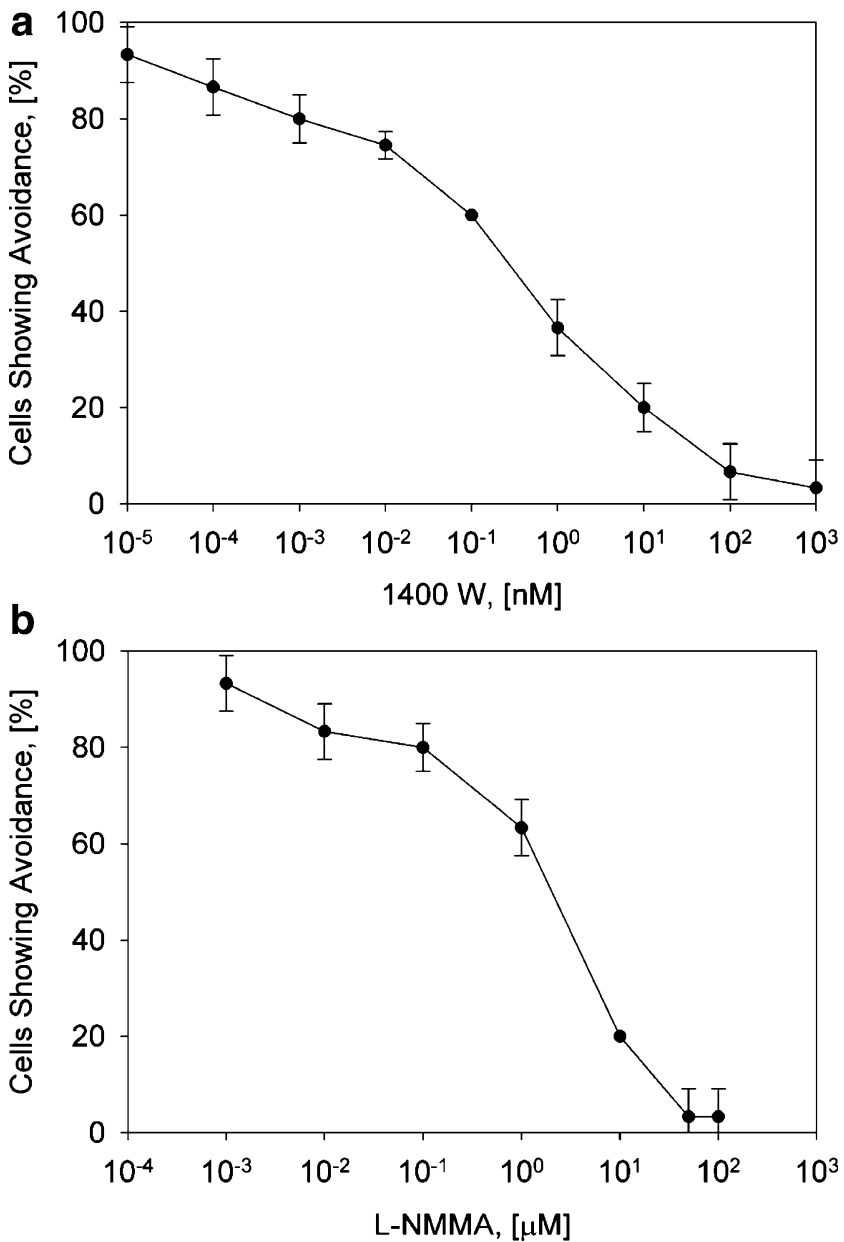

Fig. 6 Nitric oxide synthase (NOS) activity is required for guanosine 5 '-triphosphate (GTP) avoidance in Tetrahymena. a The NOS inhibitor $1400 \mathrm{~W}$ blocks avoidance to $100 \mu \mathrm{M}$ guanosine-5'-O-(3-thio)triphosphate (GTP- $\gamma-\mathrm{S})$ in Tetrahymena. Baseline avoidance was reached at a $1400 \mathrm{~W}$ concentration of $100 \mathrm{nM}$. The inhibition constant $\mathrm{IC}_{50}$ of this compound was near $0.1 \mathrm{nM}$. Data shown is mean $+/-$ standard deviation (SD) of three trials. b The NOS inhibitor NG-monomethyl-L-arginine (L-NMMA) also blocks avoidance to $100 \mu \mathrm{M}$ GTP- $\gamma-\mathrm{S}$ in Tetrahymena. Baseline avoidance was reached at an L-NMMA concentration of $10 \mu \mathrm{M}$. The inhibition constant $\mathrm{IC}_{50}$ of this compound was near $3 \mu \mathrm{M}$. Data shown is mean $+/-$ standard deviation (SD) of at least three trials

Many tyrosine kinase pathways involve phospholipase C. In various Tetrahymena species, evidence for phospholipase $\mathrm{C}$ involvement has been seen in stomatin-induced differentiation [24] and in commitment to cell survival or death [25]. Studies by Leondaritis and Galanopoulou [26] suggest that Tetrahymena possess a functional phosphatidylinositol signaling system that is similar to higher eukaryotes. Indeed, in our previous studies of PACAP [10] and ATP [13], phospholipase C involvement is also implicated. In our current study, we found that U73122 effectively eliminated GTP avoidance (Fig. 4), indicating that phospholipase $\mathrm{C}$ signaling is involved in behavioral avoidance. However, our calphostin C data (see "Results") indicate that $\mathrm{PKC}$, a common downstream target of phospholipase $\mathrm{C}$, is not required for GTP avoidance. $\mathrm{IP}_{3}$, a second messenger generated by phospholipase $\mathrm{C}$, is likely involved in GTP signaling. Although we could not test $\mathrm{IP}_{3}$ involvement directly using our behavioral assay, the fact that the ER calcium ATPase inhibitor thapsigargin eliminated GTP avoidance (Fig. 5b) is indirect evidence that $\mathrm{IP}_{3}$ may be binding to the ER and causing release of calcium from internal stores.

Calcium is a ubiquitous signaling molecule and has been implicated in ciliary reversal in Tetrahymena. It was no surprise, then, that BAPTA-AM eliminated GTP avoidance

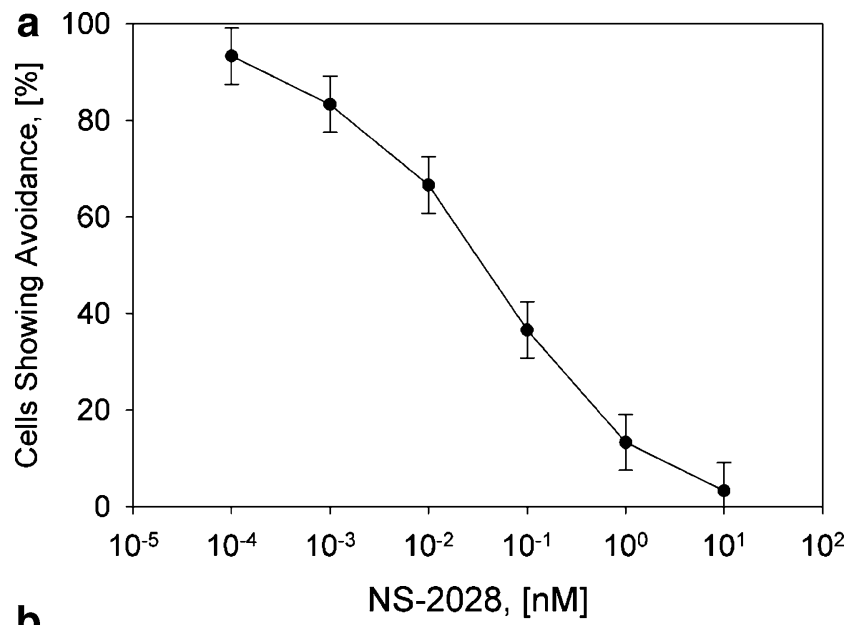

b

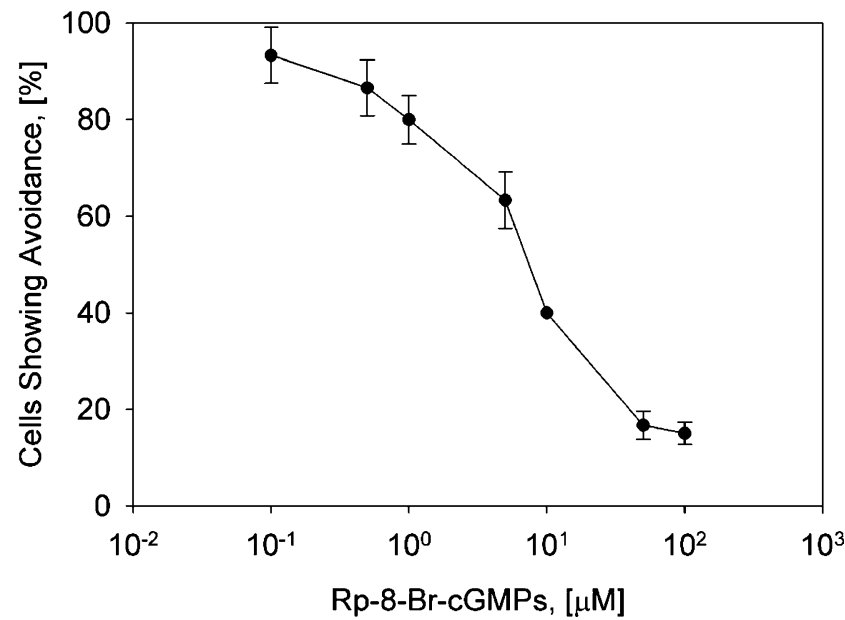

Fig. 7 Guanylyl cyclase activity is required for guanosine 5'triphosphate (GTP) avoidance in Tetrahymena. a 4H-8-bromo-1,2,4oxadiazolo(3,4-d) benz(b)(1,4)oxazin-1-one (NS2028), an inhibitor of guanylyl cyclase, blocked avoidance to $100 \mu \mathrm{M}$ guanosine-5'-O-(3thio)triphosphate (GTP- $\gamma-\mathrm{S})$ in Tetrahymena. Baseline avoidance was obtained at $10 \mathrm{nM}$. The inhibition constant $\mathrm{IC}_{50}$ of NS2028 was approximately $0.05 \mathrm{nM}$. Data shown is mean + standard deviation (SD) of three trials. b Rp-8-Bromoguanosine-3',5'-cyclic monophosphorothioate (Rp-8-Br-cGMPs), a competitive inhibitor of guanosine 3'3;5'monophosphate (cGMP), also blocked avoidance to $100 \mu \mathrm{M}$ GTP- $\gamma$-S in Tetrahymena. Baseline avoidance was obtained at $50 \mu \mathrm{M}$. The $\mathrm{IC}_{50}$ of Rp-8-Br-cGMPs was approximately $7 \mu \mathrm{M}$. Data shown is mean + standard deviation (SD) of three or more trials 
Fig. 8 Current model of guanosine 5'-triphosphate (GTP) signaling. Based on data obtained in this experiment, GTP appears to signal through a receptor linked to a tyrosine kinase. Phospholipase $\mathrm{C}$, intracellular calcium release, nitric oxide (NO) production, and guanylyl cyclase are all involved in GTP avoidance. Some of the relationships between pathway components remain unknown. This model is based on the data presented in this paper, along with data obtained from the literature $[26,32,33]$

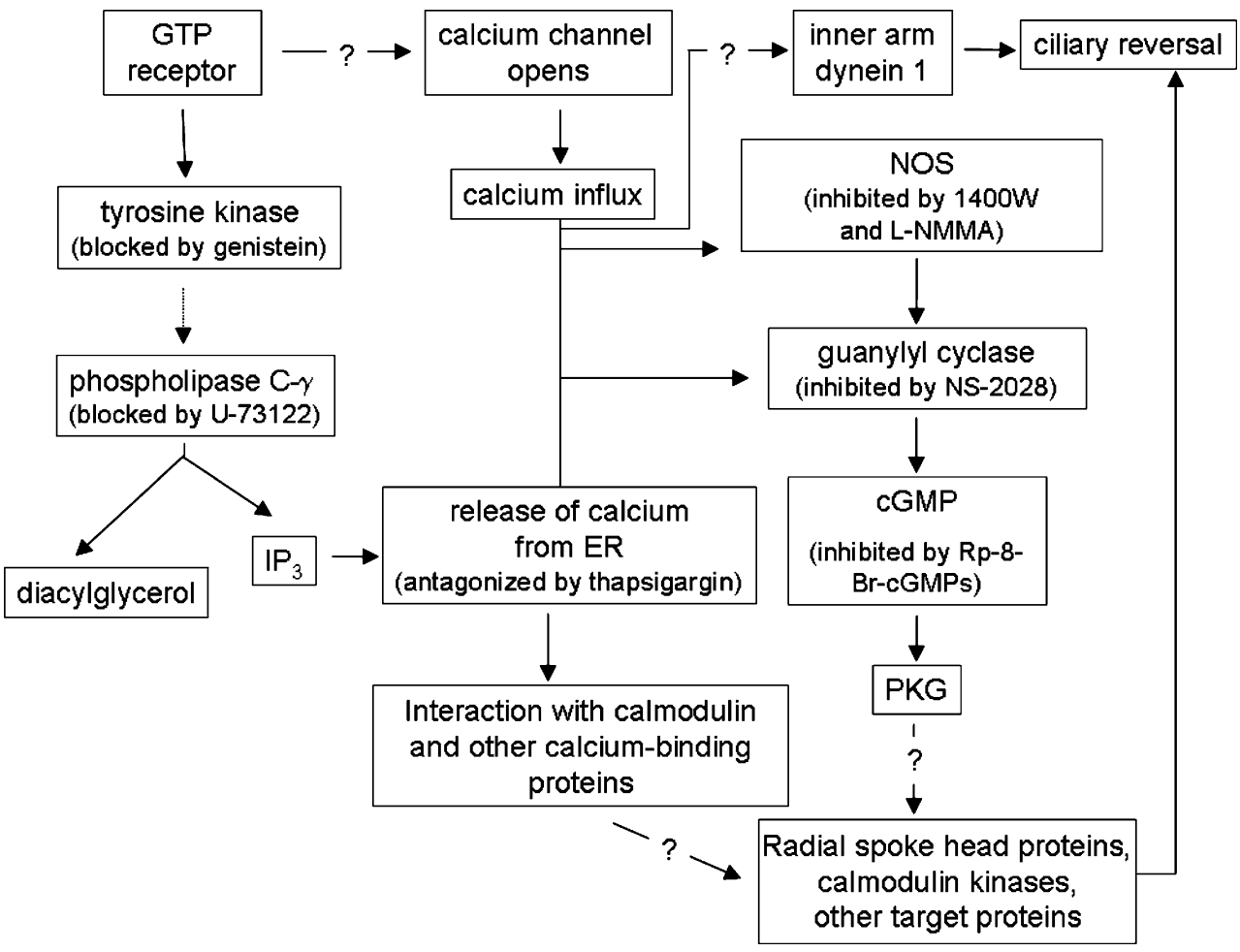

(Fig. 5a), as it has previously been shown to eliminate avoidance to PACAP [18] and ATP [13]. Calcium is likely to play multiple roles in signaling. One possible scenario is the direct interaction of calcium with ciliary motor proteins. For example, inner arm dynein 1 (I1) is required for calcium-dependent ciliary reversals in T. thermophila [27]. In this study, a "calcium sensor," which interacts with I1, was postulated. This calcium sensor protein remains to be isolated.

Intracellular calcium may also play other, less direct, roles in GTP avoidance. Indeed, in the protozoan parasite Leishmania donovani, both NOS and guanylyl cyclase are activated by intracellular calcium [28]. Both NOS (Fig. 6) and guanylyl cyclase (Fig. 7) activity are required for GTP avoidance. Previous studies that implicate NOS and guanylyl cyclase in Tetrahymena [13, 18, 19] do not indicate the type of NOS or guanylyl cyclases involved, though Christensen et al. [19] give evidence for a soluble guanylyl cyclase. In $L$. donovani, there is evidence for a constitutive, neuronal-type NOS that then activates a soluble guanylyl cyclase [28]. Both of these enzymes are activated by intracellular calcium. Our data would be consistent with a similar mechanism in Tetrahymena, as proposed in our model of GTP signaling (Fig. 8). However, neither a soluble guanylyl cyclase nor an nNOS isoform have been purified from Tetrahymena to date.

Calcium-binding proteins, such as calmodulin, may also be involved in GTP signaling in Tetrahymena, either by interacting with enzymes that generate second messengers or by interacting with the molecular motors responsible for ciliary reversal. Previous studies [29, 30] indicate that calmodulin activates a ciliary guanylyl cyclase in this organism. Our studies leave open the possibility that this cyclase, activated by calcium/calmodulin, is involved in GTP signaling. In addition to this enzyme, Hirano-Ohnishi and Watanabe [31] reported a calmodulin-dependent phosphorylation of ciliary beta tubulin in Tetrahymena, which they believe to be involved in ciliary reversal. Elongation factor $1 \alpha$, which functions in protein translation, also interacts with ciliary calmodulin [32]. Whereas this would not necessarily function in ciliary reversal, it may modulate some of the longer-term effects of GTP. Finally, Ueno et al. [33] report that ciliary calmodulin interacts with proteins that are homologues of radial spoke proteins in Chlamydomonas, further implicating calmodulin directly in ciliary reversal. We have added some of these proteins to our model of GTP signaling (Fig. 8), though there are doubtless more proteins to be discovered.

In this study, we used behavioral assays and pharmacological inhibitors to explore the intracellular mechanisms employed in GTP signaling in T. thermophila. Because pharmacological inhibitors often have unknown side effects, we used multiple inhibitors when available. Some of these inhibitors had to be used at higher concentrations in our study than have been previously published for mammalian cells. Perhaps this is because of the differences in the structure of the Tetrahymena proteins compared with their mammalian counterparts. Recognizing the potential 
pitfalls of relying solely upon pharmacological data, we supplemented behavioral assays with other kinds of tests, such as Western blots, immunofluorescence, and EIA when available. In all cases, the additional tests confirmed the data we originally obtained using pharmacological inhibitors.

Taken together, our data indicate that a number of enzymes are involved in GTP signaling. However, further experimentation is needed to discern the interrelationships between enzymes in the pathway and to answer the myriad questions that remain. For example, are guanylyl cyclase and NOS truly activated by calcium in Tetrahymena? Would calcium chelation abolish their activity? Is there a soluble guanylyl cyclase in Tetrahymena? What NOS isoforms do Tetrahymena possess? Is tyrosine phosphorylation required for either NOS or guanylyl cyclase activity? Are any additional proteins, particularly ciliary proteins, involved in GTP signaling? Are all of the components of the pathway located in the cilia? These and many other questions remain to be answered. One question we have begun to answer is whether intracellular calcium is required for tyrosine kinase activity. Recent immunofluorescence shows no difference in phosphotyrosine levels between GTP-treated cells and GTP-treated cells that had been pretreated with BAPTA-AM (unpublished data). Similarly, calcineurin (PP2B) does not appear to be involved in GTP signaling, as ascomycin treatment had no effect on GTP avoidance (unpublished data). Endothall, a PP2A inhibitor, did inhibit avoidance (unpublished observation), consistent with observations by Deckman and Pennock [33] that PP2A is involved in ciliary reversal. Further experimentation will help us determine the interrelationship of pathway components and better establish the mechanism by which chemorepellents signal in Tetrahymena.

Acknowledgements We would like to thank Matthew Tabbut for his help putting the immunofluorescence images together. We would like to thank Dara Fraley for her help scanning our Western blot.

\section{References}

1. Kuruvilla HG, Kim MY, Hennessey TM (1997) Chemosensory adaptation to lysozyme and GTP involves independently regulated receptors in Tetrahymena thermophila. J Euk Microbiol 44 (3):263-268

2. Kim MY, Kuruvilla HG, Raghu S et al (1999) ATP reception and chemosensory adaptation in Tetrahymena thermophila. J Exp Biol 202:407-416

3. Hennessey TM (2005) Responses of the ciliates Tetrahymena and Paramecium to external ATP and GTP. Purinergic Signalling $1: 101-110$

4. Iwamoto M, Nakaoka Y (2002) External GTP binding and induction of cell division in starved Tetrahymena thermophila. Eur J Cell Biol 81:517-524
5. Corti C, L'Hostis EL, Quadroni M et al (1999) Tyrosine phosphorylation modulates the interaction of calmodulin with its target proteins. Eur J Biochem 262:790-802

6. Sales ME, Sterin-Borda L, De Bracco, MME et al (1999) Tyrosine kinase regulatory action on ileal muscarinic effects of interferon gamma. J Interferon Cytokine Res 19(4):375-382

7. Munaron L (2002) Calcium signalling and control of cell proliferation by tyrosine kinase receptors. Int $\mathrm{J}$ Mol Med 10:671-676

8. Dentler WL (1988) Fractionation of Tetrahymena ciliary membranes with Triton X-114 and the identification of a ciliary membrane ATPase. J Cell Biol 107(6):2679-2688

9. Mace SR, Dean JG, Murphy, JR et al (2000) PACAP-38 is a chemorepellent and agonist for the lysozyme receptor in Tetrahymena thermophila. J Comp Physiol A 186(1):39-43

10. Hassenzahl DL, Yorgey NK, Keedy MD et al (2001) Chemorepellent signaling through the PACAP/lysozyme receptor occurs through both cAMP and PKC in Tetrahymena thermophila. J Comp Physiol A 187:171-176

11. Haddad A, Turkewitz AP (1997) Analysis of exocytosis mutants indicates close coupling between regulated secretion and transcription activation in Tetrahymena. Proc Natl Acad Sci USA 94:10675-10680.

12. Doran SA, Goldberg JI (2006) Roles of $\mathrm{Ca} 2+$ and protein kinase $\mathrm{C}$ in the excitatory response to serotonin in embryonic molluscan ciliary cells. Can J Physiol Pharmacol 84(6):635-646

13. Rosner BN, Bartholomew JN, Gaines CD et al (2003) Biochemical evidence for a P2Y-like receptor in Tetrahymena thermophila. J Comp Physiol A 189:781-789

14. Kuruvilla HG, Hennessey TM (1998) Purification and characterization of a novel chemorepellent receptor from Tetrahymena thermophila. J Membrane Biol 162:51-57

15. Kuruvilla HG, Hennessey TM (1999) Chemosensory responses of Tetrahymena thermophila to $\mathrm{CB}_{2}$, a 24-amino-acid fragment of lysozyme. J Comp Physiol A 184:529-534

16. Moritoki H, Hisayama T, Takeuchi $\mathrm{S}$ et al (1995) Possible involvement of tyrosine kinase in the LPS-promoted initiation of L-arginine-induced relaxation of rat aorta mediated by induction of NO synthase. Life Sci 57(11):125-130

17. Welshans K, Rehder V (2005) Local activation of the nitric oxide/ cyclic guanosine monophosphate pathway in growth cones regulates filopodial length via protein kinase $G$, cyclic ADP ribose, and intracellular $\mathrm{Ca}^{2+}$ release. Eur J Neurosc 22:30063016

18. Lucas J, Riddle M, Bartholomew J et al (2004) PACAP-38 signaling in Tetrahymena thermophila involves NO and cGMP. Acta Protozool 43:15-20

19. Christensen ST., Kemp K, Quie H et al (1996) Cell death, survival, and proliferation in Tetrahymena thermophila. Effects of insulin, sodium nitroprusside, 8-bromo cyclic GMP, $\mathrm{N}^{\mathrm{G}}$-methyl-Larginine, and methylene blue. Cell Biol Int 20(10):653-666

20. Linder JE, Schultz JE (2002) Guanylyl cyclases in unicellular organisms. Mol Cell Biochem 230:149-158

21. Keedy M, Yorgey N, Hilty J et al (2003) Pharmacological evidence suggests that the lysozyme/PACAP receptor of Tetrahymena thermophila is a polycation receptor. Acta Protozool 42:11-17

22. Christensen ST, Guerra CF, Awan A et al (2003) Insulin receptorlike proteins in Tetrahymena thermophila ciliary membranes. Curr Biol 13(2):R50-R52

23. Ryals PE, Bae S, Patterson CE (1999) Evidence for early signaling events in stomatin-induced differentiation of Tetrahymena vorax. J Euk Microbiol 46(1):77-83

24. Rasmussen M, Rasmussen L (2000) Phospholipase C and D in the commitment to survival or death in the early lag phase of Tetrahymena cultures. Cell Biochem Funct 18:133-139 
25. Leondartis G, Galanopoulou D (2000) Characterization of inositol phospholipids and identification of a mastoparan-induced polyphosphoinositide response in Tetrahymena pyriformis. Lipids 35 (5):525-532

26. Hennessey TM, Kim DY, Oberski DJ et al (2002) Inner arm dynein 1 is essential for $\mathrm{Ca}^{++}$-dependent ciliary reversals in Tetrahymena thermophila. Cell Motil Cytoskel 53:281-288

27. Karmarkar S, Ukil A, Mukherjee S et al (2006) Regulation of guanylyl cyclase by intracellular $\mathrm{Ca}^{2+}$ in relation to the infectivity of the protozoan parasite, Leishmania donovani. Internat $\mathrm{J}$ Biochem Cell Biol 38:1277-1289

28. Kovacs P, Csaba G, Nagao S et al (1989) The regulatory role of calmodulin-dependent guanylate cyclase in association with hormonal imprinting in Tetrahymena. Microbios 59(239):123-128
29. Umeki S, Nozawa Y (1996) Adenylate and guanylate cyclases in Tetrahymena. Prog Mol Subcell Biol 17:40-60

30. Hirano-Ohnishi J, Watanabe Y (1989) $\mathrm{Ca}^{2+} /$ calmodulin-dependent phosphorylation of ciliary beta-tubulin in Tetrahymena. J. Biochem (Tokyo) 105(6):858-860

31. Ueno H, Kohsuke G, Takeda $T$ et al (2003) Identification of elongation factor- $1 \alpha$ as a $\mathrm{Ca}^{2+} /$ calmodulin binding protein in Tetrahymena cilia. Cell Motil Cytoskel 55:51-60

32. Ueno H, Iwataki $Y$, Numata $\mathrm{O}$ (2006) Homologues of radial spoke head proteins interact with $\mathrm{Ca}^{2+} /$ calmodulin in Tetrahymena cells. J. Biochem. (Tokyo) 140:525-533

33. Deckman CM, Pennock DG (2004) Dephosphorylation of inner arm 1 is associated with ciliary reversals in Tetrahymena thermophila. Cell Motil Cytoskel 57:73-83 